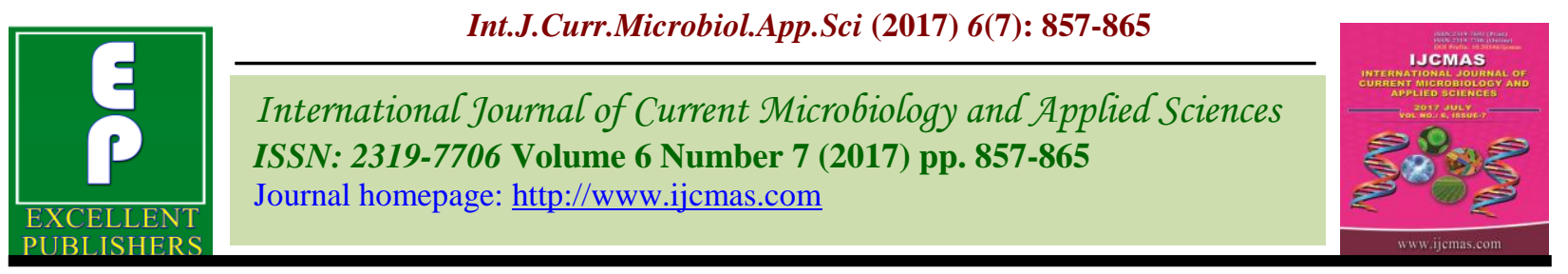

Original Research Article

https://doi.org/10.20546/ijcmas.2017.607.105

\title{
Effect of Methyl Jasmonate on Disease Severity and Expression of Plant Defensin Gene during Alternaria brassicae Infection in Arabidopsis
}

\author{
Snigdha Tiwari", Dinesh Pandey, Manu Gaur and Anil Kumar \\ Department of Molecular Biology and Genetic Engineering, G. B. Pant University of Agriculture \\ and Technology, Pantnagar-263145, Uttarakhand, India \\ *Corresponding author
}

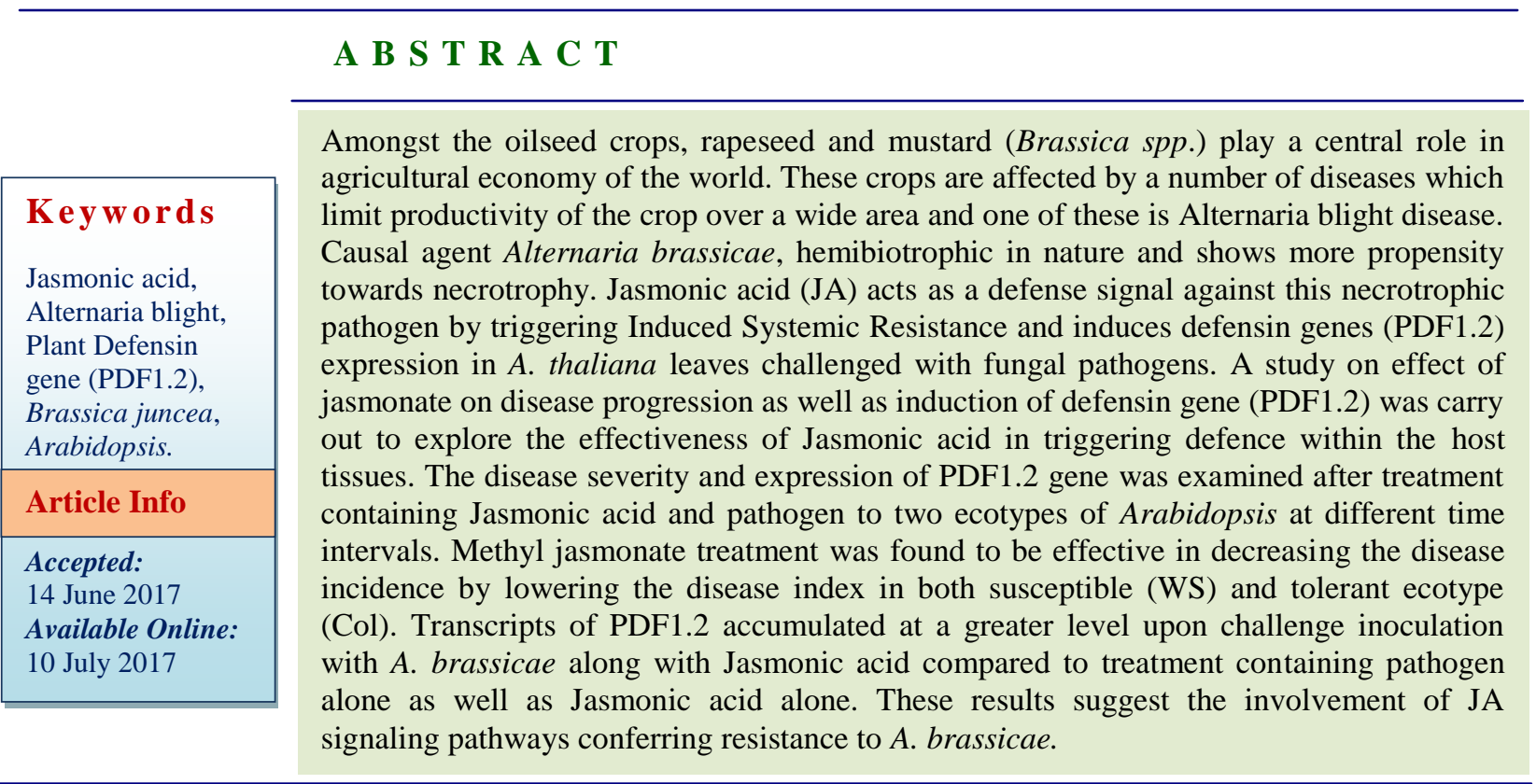

\section{Introduction}

India ranked fourth in production of rapeseedmustard having production of 58.03 lakh tonnes and 0.94 tonnes/hectare productivity in 2014-15 (Mustard Seed Survey Report 201415), contributing upto $11 \%$ of world's total production. Despite high productivity the per capita availability of rapeseed edible oilseed has been very low due to many diseases. Among several diseases Alternaria blight is one of the important diseases caused by Alternaria brassicae causing 30-70\% yield loss of Brassica crops (Mishra et al., 2010). It produces disease determinants like chlorotic necrotic toxins and phytohormones to causes chlorosis, necrosis, and Green Island like disease symptoms in susceptible Brassica plants. Although it was shown that the chlorotic toxin interacts with components of cell cycle machinery and triggers programmed cell death (Khandelwal et al., 2002; Pandey et al., 2001) yet definite molecular target of toxin or pathogen could not be delineated. It is being felt that identification of target molecule affected by either pathogen or toxin is key step before designing biotechnological strategies to 
combat the disease (Dumka, 2012). During plant-pathogen interaction, responses of plants/host towards the pathogen occurred through signal transduction (Gómez-Vásquez et al., 2004). Plants can activate separate defense pathways depending on the type of pathogen encountered (Garcia-brugger et al., 2006]. Jasmonates and ethylene dependent responses seem to be initiated by necrotrophs, whereas salicylic acid (SA) dependent response is activated by biotrophic pathogens. In case of hemibiotrophic pathogen, both SA and JA are involved in defense against this pathogen.

Jasmonates have various functions such as in plant defense as part of the multifaceted signaling pathways, regulate a variety of plant-developmental responses like embryogenesis, pollen and seed development, and root growth (Creelman and Mullet, 1997; Farmer et al., 2003; Liechti et al., 2006) and is also induced by biotic stresses such as insect or pathogen attack and abiotic stresses. JA responses are generally considered effective in defense against necrotrophic pathogens (Turner et al., 2002; Farmer et al., 2003). JA- mediated signaling appears to work in concert with ET- mediated responses and plant defensin gene (PDF1.2)expression depends on both hormones (Farmer et al., 2003; Guo and Ecker, 2004).Arabidopsis mutants impaired in the synthesis (fad3/7/8) or perception (coi1) of JA showed increased susceptibility to fungal pathogens like Alternaria brassicicola, Botrytis cinerea, and Pythium sp., and E. carotovora, a bacterial pathogen (Thomma et al., 1998, 2001; Norman-Setterblad et al., 2000). Plant defensins are $5 \mathrm{kDa}$, cysteine-rich, cationic peptides (Broekaert et al.,1995; Broekaert et al., 1997) exhibit antimicrobial properties in vitro, particularly against filamentous fungi, thus believed to contribute to the defence arsenal of plants directed against phytopathogens like $A$. brassicicola, $B$. cinerea etc. Ntui et al., (2010) produced Egusi melon (Colocynthis citrullus L.) harbouring wasabi defensin gene confers resistance to Alternaria leaf spot and Fusarium wilt. Chamil et al., (2014) reported the expression of PDF1.2 after inoculation of the seedlings of Camelina sativa with $A$. brassicae at different time intervals and transcript accumulated at a greater level upon challenge inoculation with $A$. brassicae locally as well as systemically. In addition to this, Methyl jasmonate also induced defenserelated genes i.e. PDF1.2 which is often used as a marker gene for jasmonic acid (JA) signalling pathway to varied levels.

As $A$. brassicae follows necrotrophic nature during its disease progression in host plants and in order to combat the pathogen attack plants triggers defence signal by activating phytohormones signal pathway like ethylene, Jasmonic acid etc. biosynthesis which in turn activate several defence genes. The objective of our study was to determine whether application of JA have an effect on disease progression and expression of plant defensin gene during Alternaria brassicae infection in Arabidopsis plants.

\section{Materials and Methods}

\section{Plant material and MeJA treatment}

Arabidopsis thaliana ecotype WS and Columbia (Col) were grown in sterilized soil under optimum conditions in polyhouse, Department of Molecular Biology and Genetic Engineering, Pantnagar. In a preliminary study, we found that $25 \mu \mathrm{MMeJA}$ results in significant reduction in disease incidence. Since at this concentration, the proper balance of minimum toxicity to plant and maximum efficiency to decrease disease incidence was observed (in the form of decreased number of disease lesions) in the treated leaves of both the ecotype as 
compared to control plants. Thus this particular concentration of MeJA was used in present work. Arabidopsis leaves were treated with methyl jasmonate overnight before inoculation with Alternaria brassicae spores.

\section{Pathogen inoculation, incubation and leaf tissue sampling}

Alternaria brassicae spores were obtained from naturally infected susceptible variety (Varuna) of Brassica junceacv from Crop research centre, G.B.P.U.A \& T. Pantnagar. Arabidopsis plants were maintained under glass house conditions and artificial inoculation was done on one month old plants with $10^{4}$ spores $\mathrm{ml}^{-1}$ spore suspension and $10 \mu \mathrm{l}$ suspension was sprayed on the leaves of plants with the help of atomizer. The infected plants were isolated and incubated in the polyhouse at relative humidity of $80-90 \%$ and at temperatures ranging between minimum of $8^{\circ} \mathrm{C}$ and maximum $22^{\circ} \mathrm{C}$. Leaves of different treatment were collected at specified time intervals like $0,4,12,24,48,72$ (hours), $7^{\text {th }}$ day, $14^{\text {th }}$ day and 21 day after treatment given with MeJA, MeJA+pathogen, pathogen and distilled water(control)

\section{Calculation of Disease index}

The leaves of infected plants of Arabidopsis thaliana ecotypes WS and Col were examined at 21 days after infection i.e. on complete incidence of the disease to calculate the disease index. The average disease index was calculated by taking observation on thirty leaves of each variety and each treatment using the following formula (Conn et al., 1990).

Disease index $(\%)=$

Sum of all numerical ratings

No. of leaves examined (10) x Maximum $\times 100$ grade
Here, numerical grading refers to numbers in scale given by Bal and Kumar (2014).

\section{RNA isolation and semi quantitative RT- PCR}

RNA was isolated from leaves using HipurA Plant and fungal RNA Miniprep purification Spin kit (RNA Xpress Reagent from HiMedia) according to the manufacturer's instructions. RNA integrity was checked on formaldehyde-agarose gel, quantified by NanoDrop 1,000 (NanoDrop Technologies, Inc., DE, USA) and was treated with DNase I enzyme (Fermentas).

First-strand cDNA was synthesized from $1 \mu \mathrm{g}$ of total RNA and primed with Oligo (dT) (Thermo Scientific, USA) according to the manufacturer's instructions. PCR primers were designed based on the cDNA sequences of A. thaliana for PDF1.2 and actin (control) available at NCBI (http://www.ncbi.nlm.nih. gov) database using Primer 3 software. The corresponding primers are listed in table 1.

PCR was performed using a thermocycler (Eppendorf) in $12.5-\mu \mathrm{L}$ final volume including $0.5 \mu \mathrm{L}$ of $2 \mu \mathrm{g}$ cDNA template/ reaction, $1.25 \mu \mathrm{l}$ of $10 \mathrm{X}$ amplification buffer (Fermentas), $0.5 \mu 1$ of $2.5 \quad \mathrm{mM}$ deoxynucleotide triphosphates (Fermentas), $0.375 \mu \mathrm{l}$ of $1.5 \mathrm{mM}, 0.5 \mu \mathrm{l}$ of $50 \mathrm{nM}$ and $0.2 \mu \mathrm{L}$ (1 U) of Taq DNA polymerase (BangaloreGenei, Bangalore, India) and $8.725 \mu \mathrm{L}$ of PCR grade water.

PCR conditions included an initial denaturing step at $94^{\circ} \mathrm{C}$ for $5 \mathrm{~min}$, followed by 35 cycles of $94^{\circ} \mathrm{C}$ for $1 \mathrm{~min}, 58^{\circ} \mathrm{C}$ for $30 \mathrm{~s}, 72^{\circ} \mathrm{C}$ for 30 $\mathrm{s}$ with a final extension at $72^{\circ} \mathrm{C}$ for $10 \mathrm{~min}$. PCR products were separated using $1 \%$ agarose gels, stained with ethidium bromide and observed in a gel doc system (AlphaImager). 


\section{Results and Discussion}

\section{Jasmonic acid and disease index}

Upon inoculation with spores of pathogen, disease symptoms appeared at 7 DAI in both ecotypes of Arabidopsis thaliana. In order to study the differential response of both the ecotypes, percent disease index was calculated by taking observation on thirty pathogen inoculated leaves of each ecotype

Disease index for Alternaria blight was calculated by measuring the size of disease lesions and their number on the infected leaves as per the formula of Conn et al., (1990) given in materials and methods. Percent disease index is taken as a measure of susceptibility or resistance of a particular ecotype to a particular disease. Higher disease index means an ecotype is susceptible to the disease whereas a lower index suggests resistance to the disease.

The leaves of infected plants of Arabidopsis thaliana ecotypes WS and Col were collected from different treatments at Early (7DAI), Middle (14DAI) and Late (21DAI) stage of disease progression. The results on number of lesions observed under different treatments are given in figure 1 .

No disease spots were observed in the presence of jasmonic acid. In the presence of pathogen alone, the number of spots is more than the number of spots in presence of jasmonic acid and pathogen. This provided substantial evidence that jasmonic acid is inhibiting pathogenesis process.

When compared between the two ecotypes, Col had less number of spots than the WS ecotype. As the disease progresses, the number of spots increases but throughout disease progression the number of spots in Columbia are always less than that of WS.
This is true in the case of both the treatments of pathogen alone and pathogen along with jasmonic acid. This supports the view that Columbia is a tolerant ecotype as compared to WS. The disease index was calculated on full appearance of disease symptoms i.e. at 21 days after inoculation, as shown in table 2.

As is clear from table 2, WS ecotype reported a higher disease index (67.6) than Columbia ecotype (44.3) in case of inoculation of only pathogen.

In case of the treatment of jasmonic acid along with pathogen, also WS reported a higher disease index (51.6) as compared to Columbia (39.0). In the present study, MeJA treatment leads to reduction in disease index in both the ecotypes, Col and WS as compared to plants treated with Pathogen alone.

This provided substantial evidence that jasmonic acid is inhibiting pathogenesis process. MeJA of $25 \mathrm{uM}$ concentration was found to be effective in reducing the fungal colonization and disease progression. Norastehnia and Nojavan-Asghari (2006) also reported that signal transduction by MeJA

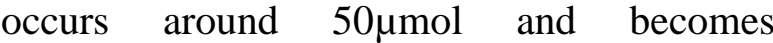
inhibitory at concentration above $100 \mu \mathrm{mol}$.

Disease index of WS plants treated with $\mathrm{JA}+$ pathogen and pathogen alone was more compared to Col plants undergone same treatment. This supports the fact that WS is more susceptible to the disease as compared to Columbia ecotype as it has reported a higher disease index in both the cases. Jasmonic acid has played a significant role in disease reduction as is evident from the significantly reduced disease index in jasmonic acid along with pathogen treatment as compared to only pathogen treatment in both the ecotypes.

Plant defensin (PDF1.2) gene expression 
To identify the expression of PDF1.2 gene in different treatments in two ecotypes of
Arabidopsis, Col and WS, a semi-quantitative PCR analysis was performed on the samples collected at different time intervals.

Table.1 Primers used in this study and their annealing temperature

\begin{tabular}{|l|l|l|}
\hline Primer & Sequence & Annealing ${ }^{\mathbf{0}} \mathbf{C}$ \\
\hline ACTIN.F & 5'GAATCCACGAGACGACTTACAAC3 $^{\prime}$ & 55.3 \\
\hline ACTIN.R & 5'CGATCCAGACACTGTACTTCCTC3 & 56.6 \\
\hline PDF1.2F & 5' CACCCTTATCTTCGCTGCTC3 & 55.6 \\
\hline PDF1.2R & 5' TGCTGGGAAGACATAGTTGC3 & 55 \\
\hline
\end{tabular}

Table.2 Influence of jasmonic acid (JA), jasmonic acid along with pathogen (P+JA) and pathogen alone $(\mathrm{P})$ on disease index of susceptible and tolerant ecotypes of Arabidopsis thaliana

\begin{tabular}{|l|l|l|l|l|}
\hline \multicolumn{1}{|c|}{ Variety } & Treatment & \multicolumn{3}{|c|}{$\begin{array}{l}\text { Time intervals (stages of } \\
\text { disease progression) }\end{array}$} \\
\hline & & $\begin{array}{l}\text { Early } \\
\text { stage } \\
\text { (7DAI) }\end{array}$ & $\begin{array}{l}\text { Middle } \\
\text { stage } \\
\text { (14DAI) }\end{array}$ & $\begin{array}{l}\text { Late } \\
\text { stage } \\
\text { (21DAI) }\end{array}$ \\
\hline $\begin{array}{l}\text { Columbia(Col) (Percent } \\
\text { disease index) }\end{array}$ & P & 19.6 & 34.0 & 44.3 \\
\hline & P+JA & 16.3 & 27.6 & 39.0 \\
\hline $\begin{array}{l}\text { WS (Percent disease } \\
\text { index) }\end{array}$ & P & 30.6 & 44.3 & 67.6 \\
\hline & P+JA & 25.3 & 35.0 & 51.6 \\
\hline
\end{tabular}

Fig.1 Effect of Jasmonic acid on number of disease lesions appeared in Columbia (Col) and WS ecotype of A. thaliana

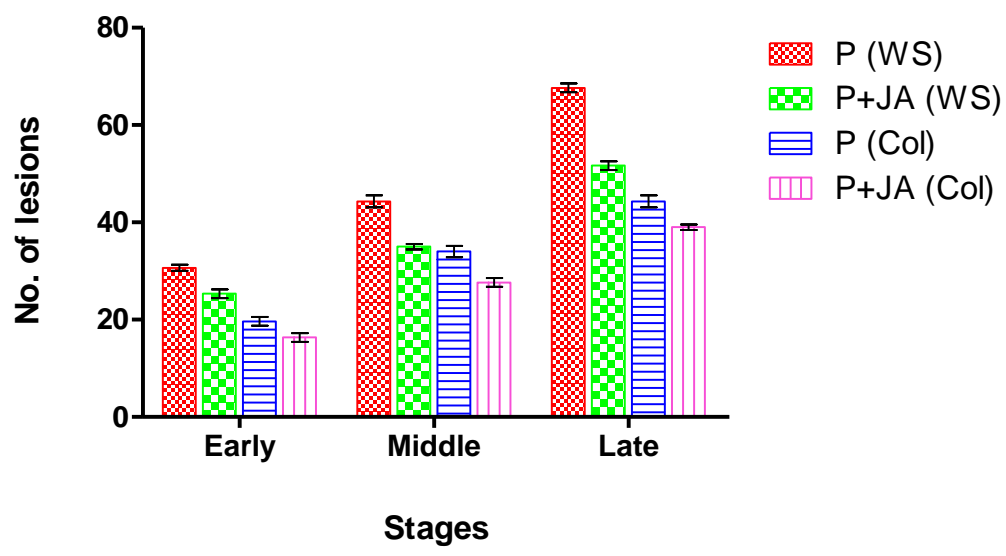


Fig.2 Time course transcript accumulation of PDF 1.2 in Jasmonic acid (A. brassicae) treated leaves of Coland WS ecotype. Total RNA was isolated from leaves at different time intervals (i.e.1: 0hr, 2: 4hr, 3: 12hr, 4: 24hr(1day), 5: 48hr (2day), 6: 72hr (3day), 7: Early (7DAI), 8: Middle (14 DAI), 9: Late(21 DAI)). Semi quantitative RT-PCR was performed from cDNA made from each RNA sample. Actin transcripts were used to normalize the sample. 35 PCR cycles were performed for all the genes

\begin{tabular}{|lllllllll|}
1 & 2 & 3 & 4 & 5 & 6 & 7 & 8 & 9 \\
\hline
\end{tabular}

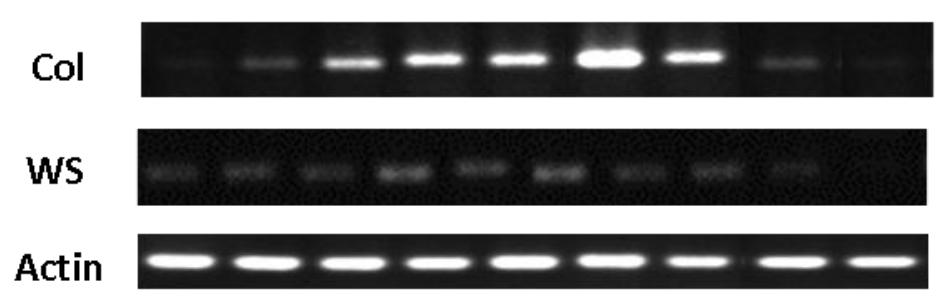

Fig.3 Time course transcript accumulation of PDF 1.2 in pathogen (A. brassicae) treated leaves of Coland WS ecotype. Total RNA was isolated from leaves at different time intervals (i.e.1: 0hr, 2: 4hr, 3: 12hr, 4: 24hr(1day), 5: 48hr (2day), 6: 72hr (3day), 7: Early (7DAI), 8: Middle (14 DAI), 9: Late(21 DAI)). Semi quantitative RT-PCR was performed from cDNA made from each RNA sample. Actin transcripts were used to normalize the sample. 35 PCR cycles were performed for all the genes

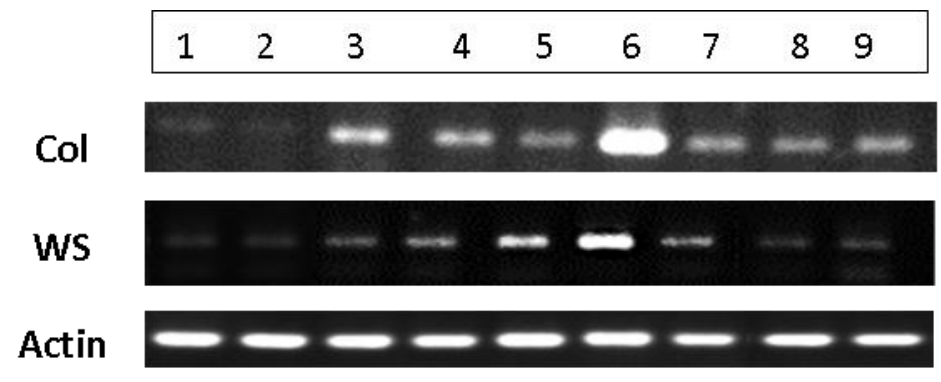

Fig.4 Time course transcript accumulation of PDF 1.2 in pathogen along with Jasmonic acid ( $A$. brassicae) treated leaves of Coland WS ecotype. Total RNA was isolated from leaves at different time intervals (i.e.1: 0hr, 2: 4hr, 3: 12hr, 4: 24hr(1day), 5: 48hr (2day), 6: 72hr (3day), 7: Early (7DAI), 8: Middle (14 DAI), 9: Late(21 DAI)).Semi quantitative RT-PCR was performed from cDNA made from each RNA sample. Actin transcripts were used to normalize the sample. 35 PCR cycles were performed for all the genes

\begin{tabular}{|lllllllll|}
\hline 1 & 2 & 3 & 4 & 5 & 6 & 7 & 8 & 9 \\
\hline
\end{tabular}

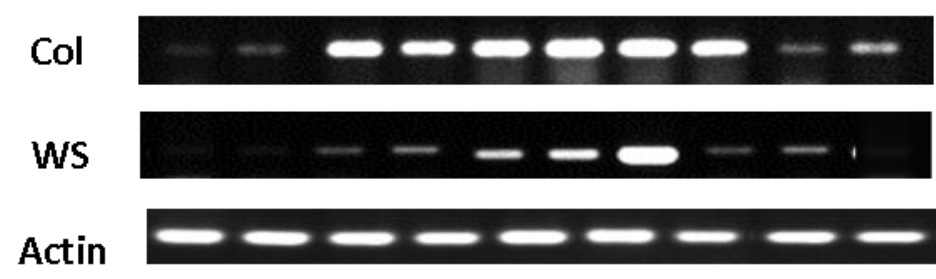


In Columbia, pre-treatment of jasmonic acid, during progression through different stages viz.0 hours, 4 hours, 12 hours, 24 hour, 48 hour, 72 hour, Early (7days) stage, Middle (14days) stage and Late (21days) stage of pathogenesis, it was observed that PDF1.2 expression showed an increase from 12 hours to 72 hours post treatment. This is in agreement with Arabidopsis defense signaling pathway that JA generally induces PDF1.2 and therefore, this gene have been extensively used as markers for JA signalling pathway (Thomma et al., 2000; Chamil et al., 2014). Again at, early, middle and late stages of disease progression the expression of PDF 1.2 continuously decreases (Fig. 2) which may be due to the feedback inhibition of endogenous levels of jasmonic acid by exogenous application of jasmonic acid. It is worth to recall that, Jasmonic acid positively regulates PDF 1.2 expression as its marker gene or induced during its treatment in arabidopsis plants (Penninckx et al., 1996). Hence, observed increase in PDF1.2 in present study suggests strengthening of jasmonic acid defense pathway. While in case of WS, expression levels were found to increase slowly from 24 hours to 72 hours, after treatment again at early, middle and late stages of disease progression the expression of PDF 1.2 decreases (Fig. 2). It was also observed that expression/ band intensity was more in Col ecotype as compared WS ecotype during this treatment.

In pathogen treatment, the expression of PDF 1.2 in Col plants started to increase at 12 hours post treatment to early stage with maximum reached at $72 \mathrm{~h}$ and early stage of disease progression respectively (Fig. 3) and then decreases till late stage while in WS plants, increase in expression was observed from $12 \mathrm{~h}$ to $72 \mathrm{~h}$ and then decrease till late stage (Fig. 3). In another study, it was reported that increase in PDF 1.2 expression during A. brassicae infection in Camelina sativa (Chamil et al., 2014). Challenge of the transgenic plants with the fungal pathogens Botrytis cinerea and Alternaria brassicicola resulted in both local and systemic induction of the GUS gene fused with the promoter of plant defensin gene (Manners et al., 1998). At later stages pathogen might overcome the defence posed by PDF 1.2 gene. The expression was found to be more in Col ecotype compared to WS ecotype.

In pathogen along with Jasmonic acid treatment, PDF1.2 showed increased expression at 12 hours after infection upto early stage in Col while in WS it showed an increase from 12 hours to 72 hours after infection and then continuously decreased as disease progressed till late stage of infection in both ecotype, Col and WS. The increased intensity of bands on the gel clearly indicated the increased expression of PDF 1.2 as compared to both pathogen and jasmonic acid treatment (Fig. 4). It implies that host plant mounts PDF 1.2 based defense response during initial interaction with pathogen which is negated by pathogen. After that, jasmonic acid mediated defense is triggered which continuously strengthen PDF 1.2 based defense and decreases pathogen colonization. But down regulation of PDF 1.2 at early, middle and late stages may be due to feedback inhibition by endogenous level of Jasmonic acid on exogenously applied Jasmonic acid. This indicates that jasmonic acid, when applied prior to pathogen inoculation is able to trigger PDF 1.2 based defense response to a greater extent and therefore decrease disease incidence. This is supported by data from the disease index. The expression was found to be more in $\mathrm{Col}$ ecotype compared to WS ecotype.

In the above study it was observed that during infection of Arabidopsis plants with Alternaria brassicae Jasmonic acid treatment was found to be effective in decreasing the 
disease incidence by lowering the disease index in both susceptible (WS) and tolerant ecotype $(\mathrm{Col})$ as compared to plants treated with pathogen alone. Along with this, Jasmonic acid induces as well as enhances the expression of PDF 1.2 in treatment containing both pathogen and Jasmonic acid plants compared to both pathogen alone and Jasmonic acid alone treatment.

\section{Acknowledgement}

We are grateful to the management of Dept. of Molecular Biology and Genetic Engineering for providing us necessary facilities and support to carry out this work.

\section{References}

Bal, R.S., and Kumar, A., 2014. Studies on the epidemiology of white rust and Alternaria leaf blight and their effect on the yield of Indian mustard. African Journal of Agricultural Research. 9(2): 302-306.

Broekaert, W.F., Terras, F.R.G., Cammue, B.P.A. and Osborn, R.W., 1995. Plant defensins: novel antimicrobial peptides as components of the host defence system. Plant Physiol 108: 1353-1358.

Broekaert, W.F., Cammue, B.P.A., De Bolle, M.F.C., Thevissen, K., De Samblanx, G.W. and Osborn, R.W. 1997. Antimicrobial peptides in plants. Crit Rev Plant Sci 16: 297-323.

Chamil, N.N.M., Rawat, S., Ali, S., and Grover, A. 2014. A-Tubulin: A more suitable internal control than $\beta$-Actin in reverse transcription-PCR analysis of Brassica juncea, Sinapis Alba and Camelina sativa under different experimental conditions. Annals of Plant Protection Sciences 22(2):345351.

Conn, K.L., Tiwari, J.P. and Awasthi, R.P., 1990. A disease assessment key for
Alternaria blackspot in rapeseed and mustard. Canadian Plant Disease Survey 70:19-22.

Creelman, R.A. and Mullet, J.E., 1997. Biosynthesis and action of jasmonates in plants. Ann. Rev. Plant Physiol. Plant Mol. Biol. 48: 355-381.

Farmer, E.E., Almeras, E. and Krishnamurthy, V., 2003. Jasmonates and related oxylipins in plant responses to pathogenesis and herbivory. Curr Opin Plant Biol. 6: 372-378.

Garcia-Brugger, A., Lamotte, O., Vandelle, E. et al., 2006. Early signaling events induced by elicitors of plant defenses. Molecular Plant-Microbe Interactions 19(7):711-724.

Gómez-Vásquez, R., Day, R., Buschmann, H., Randles, S., Beeching, J.R. and Cooper, R.M., 2004. Phenylpropanoids, phenylalanine ammonia lyase and peroxidases in elicitor-challenged cassava (Manihot esculenta) suspension cells and leaves. Annals of Botany 94(1): 87-97.

Guo, H. and Ecker, J.R., 2004. The ethylene signaling pathway: new insights. Curr Opin Plant Biol 7:40-49

Khandelwal, A., Kumar, A., Banerjee, M. and Garg, G.K.2002. Effect of Alternaria pathotoxin(s) on expression of p53-like apoptotic protein in calli and leaves of Brassica campestris. Indian J. Exp. Biol. 40(1): 89-94.

Kolte, S.J., Awasthi, R.P. and Vishwanath. 1987. Assessment of yield losses due to Alternaria blight in rapeseed and mustard. Indian Phytopath 40: 209-211. Liechti, R., Gfeller, A., and Farmer, E.E. (2006) Jasmonate Signaling Pathway. Sci. STKE 2006, cm2.

Mishra, A., Pandey, D., Goel, A. and Kumar, A.2010. Molecular cloning and in silico analysis of functional homologues of hypersensitive response gene(s) induced during pathogenesis of Alternaria blight 
in two genotypes of Brassica. J. Proteom. Bioinform. 3: 244-248.

Mustard Seed Survey Report 2014-15; www.religareonline.com

Norman-Setterblad, C., Vidal, S. and Palva E.T. 2000. Interacting signal pathways control defense gene expression in Arabidopsis in response to cell walldegrading enzymes from Erwinia carotovora. Mol Plant Microbe Interact. 13: 430-438.

Norastehnia, A. and Nojavan-Asghari, M.2006. Effect of methyl jasmonate on the enzymatic antioxidant defense system in Maize seedling subjected to paraquat. Asian J. Plant Sci. 5(1): 1723.

Ntui, V.O., Thirukkumaran, G., Azadi, P., Khan, R.S., Nakamura, I. and Mii, M., 2010.Stable integration and expression of wasabi defensin gene in "Egusi", melon (Colocynthis citrullus L.) confers resistance to Fusarium wilt and Alternaria leaf spot. Plant Cell Rep. 29:943-954

Penninckx, I.A.M.A., Eggermont, K., Terras, F.R.G., Thomma, B.P.H.J., De Samblanx, G.W., Buchala, A., Métraux, J-P., Manners, J.M. and Broekaert, W.F., 1996. Pathogen-induced systemic activation of a plant defensin gene in Arabidopsis follows a salicylic acidindependent pathway. Plant Cell 8: 2309-2323.

Thomma, B.P.H.J., Eggermont, K. Penninckx, I.A.M.A., Mauch-Mani, B., Vogelsang, R., Cammue, B.P.A. and Broekaert, W.F. 1998. Separate jasmonate-dependent and salicylatedependent defense- response pathways in Arabidopsis are essential for resistance to distinct microbial pathogens. Proc Natl Acad Sci 95:15107-15111.

Thomma, B.P.H.J., Eggermont, K., Broekaert, W.F. and Cammue, B.P.A. 2000. Disease development of several fungi on Arabidopsis can be reduced by treatment with methyl jasmonate. Plant Physiology and Biochemistry 38(5):421-427.

Thomma, B.P.H.J., Penninckx, I.A.M.A., Broekaert, W.F. and Cammue, B.P.A., 2001. The complexity of disease signaling in Arabidopsis. Curr. Opin. Immunol. (13): 63-68.

Turner, J.G., Ellis, C. and Devoto, A., 2002. The jasmonate signal pathway. Plant Cell (14): 153-164.

\section{How to cite this article:}

Snigdha Tiwari, Dinesh Pandey, Manu Gaur and Anil Kumar. 2017. Effect of Methyl Jasmonate on Disease Severity and Expression of Plant Defensin Gene during Alternaria Brassicae Infection in Arabidopsis. Int.J.Curr.Microbiol.App.Sci. 6(7): 857-865. doi: https://doi.org/10.20546/ijcmas.2017.607.105 